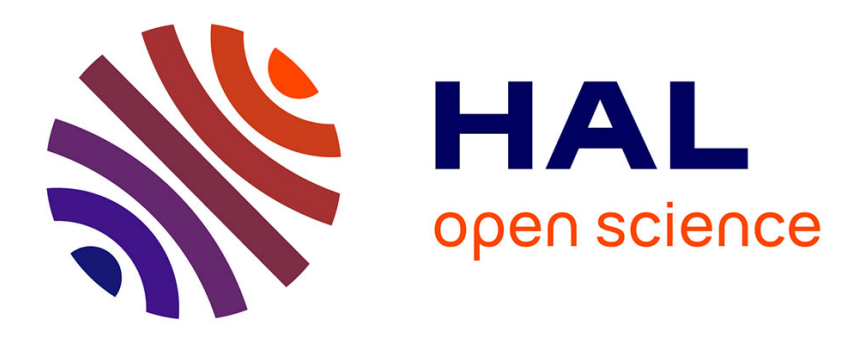

\title{
Energy conservation from systematic tire pressure regulation
}

\author{
Joshua Pearce, Jason T Hanlon
}

\section{To cite this version:}

Joshua Pearce, Jason T Hanlon. Energy conservation from systematic tire pressure regulation. Energy Policy, 2007, 35 (4), pp.2673-2677. 10.1016/j.enpol.2006.07.006 . hal-02120515

\section{HAL Id: hal-02120515 https://hal.science/hal-02120515}

Submitted on 6 May 2019

HAL is a multi-disciplinary open access archive for the deposit and dissemination of scientific research documents, whether they are published or not. The documents may come from teaching and research institutions in France or abroad, or from public or private research centers.
L'archive ouverte pluridisciplinaire HAL, est destinée au dépôt et à la diffusion de documents scientifiques de niveau recherche, publiés ou non, émanant des établissements d'enseignement et de recherche français ou étrangers, des laboratoires publics ou privés. 
This is a final draft pre-print that was published in: Joshua M. Pearce and Jason T. Hanlon, "Energy Conservation From Systematic Tire Pressure Regulation", Energy Policy, 35(4), pp. 2673-2677, 2007. Available: doi:10.1016/j.enpol.2006.07.006

\title{
Energy Conservation From Systematic Tire Pressure Regulation
}

Joshua M. Pearce* and Jason T. Hanlon

Physics Department, 106 Peirce Science Center, Clarion University of Pennsylvania, Clarion, PA 16214

\begin{abstract}
The majority of U.S. drivers do not consistently monitor the tire pressures in their vehicles. The 2000 TREAD Act, which requires automakers to gradually provide tire pressure monitoring systems for vehicles sold in the U.S. will correct this problem for new vehicles. This law does not impact the problem in previously deployed vehicles, which have a turnover time of $\sim 20$ years. A solution is provided here to address underinflated tires on the current 220 million vehicles and the concomitant wasted energy due to increased rolling resistance in the U.S. automobile fleet. This communication reports on a preliminary study of tire pressures in randomly chosen vehicles, which were undergoing oil changes at a combined retail/auto-care facility. The study indicates that substantial benefits would accrue if car care facilities systematically offered complimentary tire pressure checks with oil changes including: i) increased safety by decreasing all crashes and saving more than 100 lives, ii) reduced petroleum consumption by over a billion gallons/year, which would iia) provide over $\$ 4$ billion in economic savings for U.S. consumers that could in part be recouped in retail/auto-care facilities, iib) reduce greenhouse gas emissions by 13.5 million tons and automobile pollution and iic) enhance national security.
\end{abstract}

Keywords: energy conservation, tire pressure, fuel economy, fuel efficiency, automobile transportation, gas mileage, TREAD Act

\section{Introduction:}

The benefits are well established for reduced reliance on oil and the concomitant carbon dioxide $\left(\mathrm{CO}_{2}\right)$ emissions of its combustion, yet the United States remains reluctant to implement significant major policies to increase the energy efficiency of its vehicle fleet despite consistent support for such action by two-thirds to three-quarters of the public (Greene, 1998). A number of policies could produce higher fuel economy, reduced oil use, and lower greenhouse gas (GHG) emissions, but even the most modest changes are often under utilized (Difiglio, 1997; DeCicco, and Mark, 1998; Greene, et al., 2005). Fortunately, other factors, such as safety enhancements, can coincide with increased fuel economy. For example, to address challenges and safety concerns created by America's increased use of sports utility vehicles (SUVs), the National Highway Traffic Safety Administration created, and the U.S. $106^{\text {th }}$ Congress passed, the Transportation Recall

\footnotetext{
* Author to whom correspondence should be addressed. Phone:814-393-2713, Fax: 814-393-1630, email: jpearce@ clarion.edu
} 
This is a final draft pre-print that was published in: Joshua M. Pearce and Jason T. Hanlon, "Energy Conservation From Systematic Tire Pressure Regulation", Energy Policy, 35(4), pp. 2673-2677, 2007. Available: doi:10.1016/j.enpol.2006.07.006

Enhancement, Accountability and Documentation (TREAD) Act (2000). The TREAD Act requires automobile companies to report defects in motor vehicles, tires, or equipment and requires faulty equipment to be replaced or repaired at no cost to the consumer. The TREAD Act will also reduce energy use because it demands that manufactures install a tire pressure monitoring system (TPMS) in future automobiles. The deployment of TPMS, which consists of a tire pressure sensor in each tire, a logic circuit, and a warning system for the driver, will reduce fuel use by assuring America's fleet is driving on properly inflated tires. It has already been established that the average driver does not understand, monitor, or correct vehicle tire pressure (McKenzie-Mohr, et al., 1999; DOT, 2001). The U.S. National Center for Statistics and Analysis conducted a comprehensive tire survey (DOT, 2001) to assess i) driver awareness of recommended tire pressure for their vehicles, ii) the frequency drivers monitor their tire pressure, iii) and to what extent the measured tire pressure differs from what is recommended by vehicle manufacturers. Of the 11,000 vehicles inspected at randomly selected gas stations throughout the U.S., only $30 \%$ of surveyed drivers check the pressure in their tires at least once a month and $\sim 7 \%$ do not check the pressure at all. Overall the survey found that about $26 \%$ of passenger cars and $29 \%$ of light trucks had the pressure in at least one tire $25 \%$ below the pressure recommended by the vehicle manufacturer ${ }^{1}$ (DOT, 2001). Similar results are found elsewhere in the world. For example, a recent study in Saudi Arabia found the pressure in $21 \%$ of the inspected tires was $25 \%$ or more below the vehicle manufacturer's recommended inflation settings (Ratrout, 2005). Tires typically lose about 1 pound per square inch (psi) of air pressure per month during normal driving conditions, and can lose considerably more during the change in ambient temperature (1 psi per $10^{\circ} \mathrm{F}$ drop). This is important because under-inflated tires decrease fuel economy, shorten tread life, have less lateral traction and longer stopping distances, are prone to stress damage, are more vulnerable to flat tires and thus vehicle accidents / rollovers. The TREAD Act provision for TPMS addresses the cause of these problems for future vehicles, but does not address the issue for previously deployed vehicles in the U.S., whose fleet turnover time is 15 years for 1990 models and 20 years for new vehicles (Davis and Diegel, 2002; Schäfer and Jacoby, 2006). A solution is provided here to address the tire pressure of the current 220 million vehicles on the road and its effect on energy consumption of the U.S. transportation sector (TRB, 2006).

This communication explores the idea of utilizing a profit incentive for major retailers with access to customer vehicles through their car care facilities (e.g. Sears, Pep Boys, Wal-Mart) to provide complimentary tire pressure checks in order to address the tire pressure of currently deployed vehicles that the TREAD Act misses. In this preliminary study 275 vehicles were randomly tested for tire pressure when they stopped for service at a Wal-Mart in Pennsylvania. Based on this data, the extent of under-inflated tires is verified, the effect it had on fuel efficiency for specific cars was quantified, and the economic and environmental ramifications of the status quo were calculated for 
This is a final draft pre-print that was published in: Joshua M. Pearce and Jason T. Hanlon, "Energy Conservation From Systematic Tire Pressure Regulation", Energy Policy, 35(4), pp. 2673-2677, 2007. Available: doi:10.1016/j.enpol.2006.07.006

individual vehicles. These results were then aggregated and extrapolated to the U.S. fleet to determine the viability of providing complimentary pressure checks and the results of this concept for the consumers, the business, and the nation as a whole.

\section{Background: Tire Pressure and Fuel Efficiency}

As an automobile travels, the surface of the tire and the road come into contact and must be continually peeled apart. In addition, each surface (both the tire and the road) is deformed slightly so that in effect, the wheel is rolling uphill. These effects combine to produce a rolling resistance. A ratio of 1:5.3, or more than a $2 \%$ is found for the effect on fuel economy for every $10 \%$ change in rolling resistance for highway driving and a ratio of 1:9.6, or about a $1 \%$ fuel economy change for every $10 \%$ change in rolling resistance for urban driving (Calwell, et al., 2003). Consistent with these findings, the German Umweltbundesamt reports a $30 \%$ reduction in a tire's rolling resistance can reduce a vehicle's fuel consumption from $2 \%$ to $6 \%$, depending on driving conditions and other factors (Friedrich, 2002). According to the Rubber Manufacturers' Association, when a tire is under inflated by $1 \mathrm{psi}$, the tire's rolling resistance is increased by $\sim 1.1 \%$ and that a $5 \%$ to $8 \%$ deterioration in rolling resistance performance, which equates to a roughly $1 \%$ reduction in fuel efficiency (Calwell, et al., 2003). This is similar to the review study done by Schuring and Futamura that found for each 10\% reduction in the rolling resistance coefficient the fuel efficiency increased by $1.2-2.5 \%$ for city and $0.9-2.1 \%$ for highway driving (1990). This is because inflation pressure determines tire stiffness, which has a significant influence on the contact area of the tire and pressure distribution over the contact surface. Thus, as pressure in the vehicles tires is reduced, the rolling resistance increases over the road because the surface contact area and virtual hill height is increased. When the rolling resistance is increased it takes more energy (fuel) to get the automobile to go the same distance. The relationship between tire pressure, rolling resistance, and fuel economy is complex and dynamic and is dependent on several other factors, including vehicle type and load, road and environmental conditions.

Overall, rolling resistance makes up a relatively small percentage of the losses in a typical vehicle; it accounts for about $4 \%$ of a vehicle's energy expenditure at low speeds and about $7 \%$ at highway speeds (TRB, 2006). However, these modest losses are substantial when in the context of the entire U.S., where automobile travel accounts for the largest source of energy use and GHG emissions, with petroleum combustion causing $2,438 \mathrm{Tg}$ (106 tons) $\mathrm{CO}_{2}$ or $43 \%$ of the emissions in 2004 (EPA, 2006a). Globally the situation is similar, where in 1990 the transportation sector was responsible for some $25 \%$ of the world's energy use, and $22 \%$ of the global $\mathrm{CO}_{2}$ emissions (IPCC, 1996).

\section{Preliminary Experimental Study}

Similar to other auto-care facilities in retail businesses, Wal-Mart Auto Centers have the ability to check tire pressures on vehicles that they service. The tire pressure is 
This is a final draft pre-print that was published in: Joshua M. Pearce and Jason T. Hanlon, "Energy Conservation From Systematic Tire Pressure Regulation", Energy Policy, 35(4), pp. 2673-2677, 2007. Available: doi:10.1016/j.enpol.2006.07.006

checked and corrected for every tire job and full service oil change, but in the basic oil change (economy package) this service is not provided. The economy package provides the customer an oil and oil filter change, along with grease points on the vehicle being serviced. Two hundred and seventy five vehicles receiving the economy package were randomly tested for tire pressure at a Wal-Mart service station in Cranberry, Pennsylvania. Each individual tire pressure was recorded along with the make, model, and year of the vehicle.

The experimentally recorded tire pressures were checked against the vehicle's recommended tire pressure from the manufacturer and used to determine the loss in fuel efficiency for the individual vehicle. In order to make the mileage calculations tractable only four-tire loss was used. This is conservative assumption, because the pressure used for the calculations for all four tires was that of the most inflated tire. In many cases, several tires were lower (some extremely so) than the 4-tire loss so the results represent a minimum of additional gasoline combusted. If the lop-sided under inflations were included there would be a further loss of mileage due to both the increased rolling resistance in the affected tires and the lateral vector the vehicle would follow and resultant increased friction.

The increased fuel consumption from under-inflated tires was determined by:

$$
\text { Fuel }_{\text {Extra }}(\text { gallons })=\left(\frac{d k u}{1-k u}\right)\left(\frac{p_{h}}{m_{h}}+\frac{p_{c}}{m_{c}}\right),
$$

where $m_{c}$ and $m_{h}$ are a specific vehicles city and highway mileages in miles per gallon ${ }^{2}$, $\mathrm{p}_{\mathrm{c}}$ and $\mathrm{p}_{\mathrm{h}}$ are the percentage of highway and city driving, which the EPA estimates the U.S. average as roughly $55 \%$ in the city and $45 \%$ on the highway (2006b).

In a study conducted by the California Energy Commission, going from 20 psi (very low inflation) to $45 \mathrm{psi}$ (maximum recommended inflation) yielded about a 1.5 to $2.0 \mathrm{mpg}$ difference in the fuel economy expected from each set of tires analyzed (Calwell, et al., 2003). This is a range of 0.3-0.4\% (k) loss per under inflation (u) in psi. The distance traveled per year (d) was estimated to be the national average of 11,400 miles a year (EIA, 2006a). The cost of the additional fuel was estimated utilizing the $6 / 5 / 2006$ national average cost of gasoline -- \$2.892/gallon (EIA, 2006b) and the conversion factor of 19.564 pounds of $\mathrm{CO}_{2}$ per gallon of gasoline to get the emissions due to the added rolling resistance of under-inflated tires (EIA, 2006c). In addition, driving on under-inflated tires also causes additional wearing of the tires and decreased lifetime. This will be factored into savings of embodied energy, GHG emissions, and cost in future studies.

\section{Results:}

Of the 275 vehicles in this current study the average city mileage was $20.5 \mathrm{mpg}$ and the highway mileage was $27.4 \mathrm{mpg}$. Combined fuel economy is a harmonically 
This is a final draft pre-print that was published in: Joshua M. Pearce and Jason T. Hanlon, "Energy Conservation From Systematic Tire Pressure Regulation", Energy Policy, 35(4), pp. 2673-2677, 2007. Available: doi:10.1016/j.enpol.2006.07.006

weighted $^{3}$ average of the city (55\%) and highway (45\%) fuel economy (mpg) values, which results in a total fuel economy for the vehicles studied to be $23.1 \mathrm{mpg}$. This is a little larger than the average in the U.S., with mileage of cars being 22.1 and trucks having a mileage of 17.6, this gives the total fleet an average of about $20 \mathrm{mpg}$ (TRB, 2006). Approximately $12 \%$ of the vehicles studied had inflation pressures more than 5 psi below the OEM specifications for all tires. Due to an average under inflation of $2.639 \mathrm{psi}$ in at least all four tires the average loss in fuel efficiency was between 0.162 to 0.216 $\mathrm{mpg}$ in the city and 0.216 to $0.288 \mathrm{mpg}$ on the highway. These values appear conservative as compared to the survey discussed above primarily because the DOT reported the pressure on individual tires rather than the 4-tire model used here. Analysis of individual tire's effects on fuel efficiency entails numerical simulation and physical verification that will be completed in a future study. In general one or more of the tires on each vehicle was significantly lower than the others and would have had a larger detrimental effect on fuel economy than predicted from the analysis used in this study.

By inflating the tires to the manufactures recommended pressures, each vehicle would save between 4.0 and 5.4 gallons per year, saving consumers between $\$ 11.63$ $\$ 15.58$ per year, and preventing between $78-105$ pounds of $\mathrm{CO}_{2}$ emissions per year. The entire U.S. fleet consumes some 130 billion gallons of gasoline with distance covered of some 2,600 billion miles per year (TRB, 2006). If the fleet's fuel efficiency was increased by $0.216 \mathrm{mpg}$ by proper tire inflation, each year at least 1.388 billion gallons of gasoline would be conserved, preventing over 27 billion pounds of $\mathrm{CO}_{2}$ emissions and saving consumers over $\$ 4$ billion at the pump.

\section{Discussion:}

Although the individual results of maintaining tire pressure following the method outlined in this communication are small (U.S. consumers could save about $\$ 1 / \mathrm{month} / \mathrm{vehicle}$ ) combined this can have an effect that is non-trivial. There are a number of other such examples of environmentally and economically beneficial actions or "low hanging fruit" that are not being implemented across a range of contexts that should be immediately "harvested" (Pearce and Uhl, 2003). Even the smallest changes to the efficiency of automobiles can have an enormous effect, which should not be discounted as the automobile is adopted as the dominant form of transportation by developing nations, such as China, as their economies grow at a staggering pace (Gan, 2003; Jingwang, 2003). The negative health, environmental (pollution and GHG emissions) and national security issues with the current U.S. dependence on this oil consumption are well established (Yergin, 1992; Wackernagel and Rees, 1994; DeCicco and Mark, 1998; Dunn, 2001; Greene and Plotkin, 2001) and even the smallest improvements should not be ignored - particularly if they are either cost neutral or economically advantageous. 
This is a final draft pre-print that was published in: Joshua M. Pearce and Jason T. Hanlon, "Energy Conservation From Systematic Tire Pressure Regulation", Energy Policy, 35(4), pp. 2673-2677, 2007. Available: doi:10.1016/j.enpol.2006.07.006

Since the time of this study, the Wal-Mart Tire \& Lube Express has determined the negligible marginal cost associated with checking and correcting tire pressures enables them to offer pressure checks to all of its customers at its 2,200 locations nationwide. A recent press release (2006) stated: "As part of its overall commitment to help shoppers save time and money, Wal-Mart offers a free tire pressure check service at its Tire \& Lube Express, which customers can have done while they shop." By helping customers save money such businesses will build customer loyalty, increase customer "store-hours", increase customer discretionary spending (a total of more than $\$ 4$ billion where a percentage of which will be reinvested in merchandise or services within the business), and have positive public relations value.

With the majority of vehicles traveling on without the proper inflation, retail/auto service centers can help educate their customers in the process of each oil change by letting the customer know that their tires were low and the correct way to use a pressure gauge. The customer is more apt to check the tires if they are educated and this could have a net positive effect for the business (e.g. possible sales increases of gauges) (McKenzie-Mohr and Smith, 1999; McKenzie-Mohr, et al., 1999). By increasing awareness in its consumers to the effects of low tire pressure service centers increase environmentally sound behaviors in its customers that can carry over to other behaviors (McKenzie-Mohr and Smith, 1999).

Low tire pressure not only leads to decreased fuel economy, but also leads to many unnecessary injuries and deaths. Under-inflated tires can increase the stopping distance of a vehicle, particularly on wet or slippery surfaces. In addition, when tires are under inflated, their sidewalls flex more increasing the temperature and resulting in failure. Several studies indicate, and the consensus among tire manufacturers is that under inflation in tires is a major contributor to tire failure (DOT, 2001; Aguirre, 1986). NCSA studied the data collected by the National Accident Sampling System-Crashworthiness Data System between 1995 and 1998 and estimated that over 23,000 tow-away crashes ( $0.5 \%$ of all crashes) are caused by blowouts or flat tires each year (DOT, 2001). Since this time the increased use of SUVs has increased this rate because low tire pressure is a contributing factor in rollovers, which are responsible for SUVs failing to protect their drivers from vehicle fatalities more than car drivers counter to popular beliefs (Ross and Wenzel, 2002). If all light vehicles meet the 4-tire, 25\% compliance option, the Department of Transportation estimates reductions in crashes each year due to skidding/loss of control, stopping distance, and flat tires / blowouts caused by underinflated tires would prevent 124 fatalities and 8,722 injuries would be prevented or reduced in severity (2001). The resulting increase in healthcare and insurance payouts from these injuries and deaths could as well be avoided if tire pressure was checked.

\section{Conclusions}


This is a final draft pre-print that was published in: Joshua M. Pearce and Jason T. Hanlon, "Energy Conservation From Systematic Tire Pressure Regulation", Energy Policy, 35(4), pp. 2673-2677, 2007. Available: doi:10.1016/j.enpol.2006.07.006

U.S. drivers do not adequately monitor the tire pressures in their vehicles. This study indicates that substantial benefits would accrue if automobile-care facilities offered complimentary tire pressure checks with oil changes to systematically regulate tire pressure including: increased safety, reduced petroleum consumption, increased customer discretionary spending that could be recouped in retail/auto stores, reduced pollution and GHG emissions and enhanced national security. The nearly 5,000 firms and over 8,000 establishments in the U.S. Automotive oil change \& lubrication shops (U.S. Census Bureau, 2006) should all adopt this plan immediately as it is also likely to increase their own bottom line.

\section{Notes}

\section{References}

Calwell, C., Ton, M., Gordon, D., Reeder, T., Olson, M., and Foster, S. 2003. California State Fuel Efficient Tire Report: Volume II, California Energy Commission, 600-03001CR. Available: http://www.energy.ca.gov/reports/2003-01-31_600-03001CRVOL2.PDF

Davis, S.C, and Diegel, S.W. 2002. Transportation Energy Data Book, 22 Edition. US Department of Energy, Oak Ridge National Laboratory, Center for Transportation Analysis, Oak Ridge, TN.

DeCicco, J. and Mark, J. 1998. Meeting the energy and climate challenge for transportation in the United States. Energy Policy 26(5), 395-412.

Difiglio, C. 1997. Using advanced technologies to reduce motor vehicle greenhouse gas emissions. Energy Policy 25(14-15), 1173-1178.

(DOT) Department of Transportation, 2001. National Highway Traffic Safety Administration, Federal Motor Vehicle Safety Standards, Tire Pressure Monitoring Systems, Controls and Displays. 49 CFR Part 571, [Docket No. NHTSA 2000-8572] RIN 2127-AI33.

Dunn, S. 2001. Decarbonizing the Energy Economy. In: World Watch Institute Chap. 5, State of the World 2001, W.W. Norton \& Company, New York.

(EIA) Energy Information Administration. 2006a. Transportation Energy Consumption Surveys Energy Used by Vehicles, Chapter 3. Vehicle-Miles Traveled, Available: http://www.eia.doe.gov/emeu/rtecs/chapter3.html 
This is a final draft pre-print that was published in: Joshua M. Pearce and Jason T. Hanlon, "Energy Conservation From Systematic Tire Pressure Regulation", Energy Policy, 35(4), pp. 2673-2677, 2007. Available: doi:10.1016/j.enpol.2006.07.006

(EIA) Energy Information Administration, 2006b. Weekly U.S. Retail Gasoline Prices, Regular Grade Dollars per gallon, including all taxes, Available:

http://www.eia.doe.gov/oil_gas/petroleum/data_publications/wrgp/mogas_home_page.ht $\mathrm{ml}$ (visited 6/5/2006)

(EIA) Energy Information Administration. 2006c. Fuel and Energy Source Codes and Emission Coefficients, Available: http://www.eia.doe.gov/oiaf/1605/factors.html

(EPA) Environmental Protection Agency. 2006a. Inventory of U.S. Greenhouse Gas Emissions and Sinks: 1990-2004, USEPA \#430-R-06-002, U.S. Environmental Protection Agency: Washington, D.C.

(EPA) Environmental Protection Agency, 2006b. Office of Air and Radiation and the Office of Transportation and Air Quality, "Fuel Economy and Emissions Programs Fact Sheet", Available: http://www.epa.gov/otaq/cert/factshts/fefact01.pdf.

Friedrich, A. 2002. Fuel Savings Potential From Low Rolling-Resistance Tires. Presentation for the Umweltbundesamt at the September 2002 CEC Tires Workshop in Sacramento, CA.

Gan, L. 2003. Globalization of the automobile industry in China: dynamics and barriers in greening of the road transportation. Energy Policy 31(6), 537-551.

Greene, D.L., 1998. Why CAFE worked. Energy Policy 26(8), 599-614.

Greene, D.L. and Plotkin, S. E. 2001. Energy futures for the US transport sector. Energy Policy 29(14), 1255-1270.

Greene, D. L., Patterson, P. D., Singh, M., Li, J. 2005. Feebates, rebates and gas-guzzler taxes: a study of incentives for increased fuel economy. Energy Policy 33(6) 757-775.

(IPCC) Intergovernmental Panel on Climate Change, 1996. Impacts, Adaptation and Mitigation Options, IPCC Working Group II, Cambridge University Press, Cambridge, UK.

Jingwang, L. 2003. An Update on Efforts to Promote Cleaner Vehicles in China, The Sinosphere Journal 6(1), pg 28-33. 
This is a final draft pre-print that was published in: Joshua M. Pearce and Jason T. Hanlon, "Energy Conservation From Systematic Tire Pressure Regulation", Energy Policy, 35(4), pp. 2673-2677, 2007. Available: doi:10.1016/j.enpol.2006.07.006

McKenzie-Mohr, D., LURA Consulting, and Kassirer, J. 1999. Barriers to Individual Participation in Greenhouse Gas Reduction Activities - An Evaluation. Natural Resources Canada, Office of Energy Efficiency. Public Education and Outreach Issue Table. Available: http://oee.nrcan.gc.ca/transportation/idling/material/reports-research/barriers1999-report.cfm?attr=16

McKenzie-Mohr, D., Smith W. 1999. Fostering sustainable behavior. New Society Publishers, B.C. Canada.

Pearce, J. and Uhl, C. 2003.Getting It Done: Effective Sustainable Policy Implementation at the University Level. Planning for Higher Education 31(3), 53-61.

Ratrout, N. T. 2005. Tire condition and drivers' practice in maintaining tires in Saudi Arabia. Accident Analysis and Prevention 37(1), 201-206.

Ross, M. and Wenzel, T. 2002. An Analysis of Traffic Deaths by Vehicle Type and Model. Report Number T021. American Council for an Energy-Efficient Economy: Washington, D.C.

Schäfer, A. and Jacoby, H. D. 2006. Vehicle technology under CO2 constraint: a general equilibrium analysis. Energy Policy 34(9), 975-985.

Schuring, D. J. and Futamura, S. 1990. Rolling loss of pneumatic high-way tire in the eighties. Rubber Chemistry and Technology 63(3), 315-367.

(TRB) Transportation Research Board. 2006. Tires and Passenger Fuel Economy: informing Consumers, Improving Performance, Transportation Research Board Special Report 286, National Research Council of the National Academy of Sciences: Washington, D.C.

U.S. Census Bureau. 2006. Statistics of U.S. Businesses: 2003: NAICS 811191 Automotive oil change \& lubrication United States, Available: http://www.census.gov/epcd/susb/2003/us/US811191.HTM

U.S. 106 ${ }^{\text {th }}$ Congress. 2000. Transportation Recall Enhancement, Accountability and Documentation (TREAD) Act, Public Law 106-414-Nov. 1, 2000.

Wackernagel, M. and W. Rees. 1994. Our Ecological Footprint : Reducing Human Impact on the Earth, New Society Publishers: Gabriola Island, B.C. 
This is a final draft pre-print that was published in: Joshua M. Pearce and Jason T. Hanlon, "Energy Conservation From Systematic Tire Pressure Regulation", Energy Policy, 35(4), pp. 2673-2677, 2007. Available: doi:10.1016/j.enpol.2006.07.006

Wal-Mart, 2006. Wal-Mart's Tire \& Lube Express Offers Ways to Help Drivers Maximize Miles per Gallon, Bentonville, Ark., May 18, 2006 Available:

http://www.walmartfacts.com/newsdesk/article.aspx?id=1861

Yergin, D. 1992. The Prize: The Epic Quest for Oil, Money and Power. Touchstone, New York. 
${ }^{1}$ A $25 \%$ under inflation puts a 30 psi tire at 22.5 psi

${ }^{2}$ The EPA "city test" is a 31-minute 11-mile trip with 23 stops with an average speed of about $20 \mathrm{mph}$. About $18 \%$ of the time is spent idling to simulate waiting for traffic lights and a short freeway-driving segment is included in the test. The engine is initially started after being parked overnight. The EPA "highway test" is a 10-mile trip with an average speed of $48 \mathrm{mph}$. The vehicle is started "hot" and there is very little idling and no stops.

$$
{ }_{3} m_{\text {combined }}=\frac{1}{\frac{0.55}{m_{c}}+\frac{0.45}{m_{h}}}
$$

